\section{SAT0345 QUALITY INDICATORS IN THE CARE OF PSORIATIC ARTHRITIS}

P. Helliwell ${ }^{1}$, G. Favier ${ }^{2}$, D. Gladman ${ }^{1}$, E. Soriano ${ }^{1}$, B. Kirkham ${ }^{1}$, L. Coates ${ }^{1}$, L. Puig ${ }^{1}$, W.-H. Boehncke ${ }^{1}$, D. Thaci ${ }^{1} .{ }^{1}$ Group for Research and Assessment of Psoriasis and Psoriatic Arthritis, Seattle, USA; ${ }^{2}$ Global Strategy Group, Healthcare and Life Sciences, KPMG LLP, London, UK

Background: In 2016, members of GRAPPA in collaboration with KPMG LLP (UK) conducted a study to benchmark care in psoriatic arthritis (PsA). Challenges in the care of patients with PsA were identified but a key finding was that centres do not usually have processes in place to measure the impact of improved quality of care. ${ }^{1}$

Objectives: To identify quality of care indicators to enable PsA caregivers to assess and monitor the outcomes of specific initiatives aimed at improving care in four focus areas. The focus areas are aligned to key patient pathway challenges: 1) Shorten time to diagnosis, 2) Improve multi-disciplinary collaboration, 3) Optimise disease management and 4) Improve disease monitoring

Methods: 1 . Structured review literature to obtain a longlist of 100 potential indicators across 4 focus areas. Search strategy used specific terms related to quality measures in PsA, adjacent and other chronic diseases. 80+publications were reviewed and rated based on relevance to four focus areas. 2. Survey expert rheumatologists and dermatologists representative of different healthcare systems to review the longlist and identify the most meaningful and feasible indicators for use in day to day practice. 3 . Consensus discussion among the experts to identify shortlist of indicators based on pre-defined selection criteria. Key criteria for the Indicators were: ${ }^{1}$ support improvement of patient care ${ }^{2}$ evidence-based, ${ }^{3}$ measurable, and ${ }^{4}$ feasible. 4. Electronic group discussion among the experts to refine definitions of shortlisted indicators and targets.

Results: The expert group arrived at a consensus with a shortlist of 8 quality indicators across each focus area.

Domain (Indicator, Target) 1. Shorten time to diagnosis (a) Average duration from presentation to HCP to confirmed PsA diagnosis. Less than 6 months $^{2}(b) \%$ of patients with Psoriasis who receive a PsA screening test Annually ${ }^{3}$ ). 2. Improve multidisciplinary collaboration (a) Multidisciplinary PsA assessment is available $(\mathrm{Y} / \mathrm{N})^{4}$ (b) Does the centre provide suitable training for HCPs, nurses etc. to increase awareness of PsA disease symptoms $(\mathrm{Y} / \mathrm{N})^{5} 3$. Optimise disease management (a) Average number of PsA evaluations done by HCP per patient in a year ${ }^{6} 1-2$ annually (b)\% PsA patients on whom T2T strategy is applied ${ }^{7} 4$. Improve disease monitoring (a)\% of PsA patients who received full disease assessment for co-morbidities, e.g. co-morbidity index at least once every year ${ }^{8}$ (b) Availability of short-term unscheduled appointments $(\mathrm{Y} / \mathrm{N}) ?^{9}$ Max. 2 weeks. Conclusions: 8 quality indicators in 4 areas of practice have been defined. The respective targets are evidence based, feasible, measurable and meaningful for patients.

\section{REFERENCES:}

[1] Favier, et al. J Rheumatol 2017:44(5):674-678.

[2] Haroon, et al. Ann Rheum Dis 2015;74(6):1045-50.

[3] NICE, Psoriasis: the assessment and management of psoriasis 2017.

[4] Urruticoechea-Arana, et al. Reumatol Clin 2017;24:S1699-258X(17) 30183-3.

[5] Betteridge, et al. J Eur Acad Dermatol Venereol 2016;30(4):576-585.

[6] Combe et al. Ann Rheum Dis 2016;0:1-12.

[7] Smolen, et al. Ann Rheum Dis 2014;73(1):6-16.

[8] Miedany, et al. Rheumatol Orthop Med 2017;2(2):1-7.

[9] Lebwohl, et al. Am J Clin Dermatol 2016;17:87-97.

Acknowledgements: This study was funded by Abbvie

Disclosure of Interest: None declared

DOI: 10.1136/annrheumdis-2018-eular.4292

\section{SAT0346}

CLINICALLY MEANINGFUL IMPROVEMENT IN SKIN AND NAIL PSORIASIS IN BIO-NAÏVE ACTIVE PSORIATIC ARTHRITIS PATIENTS TREATED WITH INTRAVENOUS GOLIMUMAB: RESULTS THROUGH WEEK 24 OF THE GO-VIBRANT STUDY

P.J. Mease ${ }^{1}$, M.E. Husni ${ }^{2}$, S.D. Chakravarty ${ }^{3}$, S. Kafka ${ }^{4}$, D.D. Harrison ${ }^{5}$, D. Parenti ${ }^{4}$, L. Kim ${ }^{6}$, K.H. Lo ${ }^{6}$, E.C. Hsia ${ }^{7}$, A. Kavanaugh ${ }^{8} .{ }^{1}$ Swedish Medical Center and $U$ of Wash School of Medicine, Seattle; ${ }^{2}$ Cleveland Clinic, Cleveland

${ }^{3}$ Janssen Scientific Affairs, LLC/Drexel U College of Med, Horsham/Phila;

${ }^{4}$ Janssen Scientific Affairs, LLC; ${ }^{5}$ Janssen Research and Development, LLC, Horsham; ' Janssen Research and Development, LLC, Spring House; ' Janssen Research and Development, LLC/U Penn, Spring House/Phila; ${ }^{8}$ UCSD, San Diego, USA

Background: GO-VIBRANT was a Ph3 trial of IV golimumab (GLM) in adult pts w/active PsA

Objectives: To evaluate improvement in skin, nail psoriasis and Dermatology Life Quality Index (DLQI) w/IV GLM.

Methods: Adult bio-naïve PsA pts w/active disease $(\geq 5$ swollen and tender joints, CRP $>0.6 \mathrm{mg} / \mathrm{dl}$, active plaque PsO or documented history, and despite treatment w/csDMARDs and /or NSAIDs)were randomised to IV GLM $2 \mathrm{mg} / \mathrm{kg}$ at wks 0,4 , and q8wks thereafter or PBO at wks $0,4,12$, and $20 \mathrm{w} /$ crossover to GLM at wk24. Pts $w />3 \%$ body surface area(BSA)PsO at baseline (BL) were assessed using Psoriasis Area and Severity Index(PASI,0-72) 75/90/100\% and modified Nail Psoriasis Severity Index(mNAPSI,0-130) at BL, wks14 and 24(in pts w/ mNAPSI $>0$ at $B L$ ). DLQI was assessed at $B L$, wks8, 14 and 24 .

Results: 394 pts(PBO: $n=198 ; G L M: n=196)$ had $\geq 3 \%$ BSA PsO at BL; $76.5 \%$ had mNAPSI $>0$ at $\mathrm{BL}$ (mean 18.6).Pts on GLM achieved a greater PASI75 response vs $\mathrm{PBO}(59.2 \%$ vs $13.6 \%, \mathrm{p}<0.001)$ at wk 14 and wk $24(64.8 \%$ vs $13.1 \%, \mathrm{p}<0.001)$ At wk14, pts on GLM achieved greater PASI 90/100 responses vs $\mathrm{PBO}(39.3 /$ $16.8 \%$ vs $6.6 / 4.5 \%$; $<<0.001$ for all) and at wk $24(42.9 / 25.5 \%$ vs $7.6 / 5.6 \% ; p<0.001$ for all) (table 1). At wk14, similar proportions of pts in GLM grps, regardless of BL MTX use, achieved PASI 90/100 responses. At wk24, greater proportions of pts on GLM+MTX and GLM only achieved PASI100 vs PBO(+MTX:30.5\% vs $7 \%$, $\mathrm{p}<0.001 ;-\mathrm{MTX}: 15.4 \%$ vs $1.8 \%, \mathrm{p}<0.010$ ) (table 1).Mean decrease(improvement) from $\mathrm{BL}$ in mNAPSI score was greater in GLM vs $\mathrm{PBO}(-9.6$ vs $-1.9, \mathrm{p}<0.001)$ at wk14 and wk24(-11.4 vs $-3.7, p<0.001)$. At wk8, mean decrease(improvement) from $\mathrm{BL}$ in $\mathrm{DLQ}$ was greater in GLM vs $\mathrm{PBO}(-7.2$ vs $-1.7, \mathrm{p}<0.001)$, at wk14 $(-7.7$ vs $-1.8, p<0.001)$ and wk24( -8.1 vs $-1.9, p<0.001)$. At wk $14,55.1 \%$ of pts treated w/GLM achieved a PASI50 response and improvement in DLQI $\geq 5$ vs $7.1 \%$ treated $w / P B O(p<0.001)$ and at $w k 24,59.2 \%$ vs $8.1 \%(p<0.001)$

Abstract SAT0346 - Table 1. Change from Baseline in PASI 90/100 Through Wk24

\begin{tabular}{|c|c|c|c|c|}
\hline & \multicolumn{2}{|c|}{ Wk14 } & \multicolumn{2}{|r|}{ Wk24 } \\
\hline & $\overline{\mathrm{PBO}}$ & GLM & PBO & GLM \\
\hline $\begin{array}{l}\text { Pts evaluable for improvement fr/BL in } \\
\text { PASI, n }\end{array}$ & 198 & 196 & 198 & 196 \\
\hline PASI 90 (\%) & 6.6 & 39.3 & 7.6 & 42.9 \\
\hline$\%$ Diff $(95 \% \mathrm{Cl})$ & & $\begin{array}{c}32.7(25.10 \\
40.40)^{\star}\end{array}$ & & $\begin{array}{c}35.3(27.52 \\
43.16)^{*}\end{array}$ \\
\hline PASI 100 (\%) & 4.5 & 16.8 & 5.6 & 25.5 \\
\hline$\% \operatorname{Diff}(95 \% \mathrm{Cl})$ & & $\begin{array}{c}12.3(6.34 \\
18.30)^{*}\end{array}$ & & $\begin{array}{l}20.0(13.22 \\
26.85)^{\star}\end{array}$ \\
\hline +BL MTX, n & 142 & 131 & 142 & 131 \\
\hline PASI 90 (\%) & 7.7 & 41.2 & 9.2 & 45.8 \\
\hline$\% \operatorname{Diff}(95 \% \mathrm{Cl})$ & & $\begin{array}{c}33.5(23.97 \\
42.98)^{\star}\end{array}$ & & $\begin{array}{c}36.6(26.88 \\
46.41)^{*}\end{array}$ \\
\hline PASI 100 (\%) & 5.6 & 17.6 & 7.0 & 30.5 \\
\hline$\% \operatorname{Diff}(95 \% \mathrm{Cl})$ & & $\begin{array}{c}11.9(4.39 \\
19.46)^{\star \star}\end{array}$ & & $\begin{array}{l}23.5(14.55, \\
32.43)^{*}\end{array}$ \\
\hline - BL MTX, n & 56 & 65 & 56 & 65 \\
\hline PASI 90 (\%) & 3.6 & 35.4 & 3.6 & 36.9 \\
\hline$\% \operatorname{Diff}(95 \% \mathrm{Cl})$ & & $\begin{array}{c}31.8(19.21 \\
44.41)^{\star}\end{array}$ & & $\begin{array}{c}33.4(20.65 \\
46.05)^{\star}\end{array}$ \\
\hline PASI 100 (\%) & 1.8 & 15.4 & 1.8 & 15.4 \\
\hline$\% \operatorname{Diff}(95 \% \mathrm{Cl})$ & & $\begin{array}{l}13.6(4.17 \\
23.03)^{\star \star \star}\end{array}$ & & $\begin{array}{l}13.6(4.17 \\
23.03)^{\star \star *}\end{array}$ \\
\hline${ }^{*} \mathrm{p}<0.001 ;{ }^{* *} \mathrm{p}=0.002 ;{ }^{* *} \mathrm{p}=0.010$ & & & & \\
\hline
\end{tabular}

Abstract SAT0346 - Table 2. Change from Baseline in mNAPSI Through Wk24

\begin{tabular}{lcccc}
\hline & \multicolumn{2}{c}{ Wk14 } & \multicolumn{2}{c}{ Wk24 } \\
\cline { 2 - 5 } & PBO & GLM & PBO & GLM \\
\hline Pts (mNAPSI>0) evaluable for & 170 & 197 & 170 & 197 \\
change fr/BL, $n$ & & & & \\
Mean (SD) & -1.9 & $-9.6(15.71)$ & -3.7 & $-11.4(16.38)$ \\
LS Mean diff (95\% Cl) & $(13.05)$ & $-8.4(-10.71,-$ & $(14.45)$ & $-8.4(-10.82,-$ \\
& & $6.05)^{*}$ & & $6.01)^{\star}$ \\
\hline
\end{tabular}

${ }^{*} \mathrm{p}<0.001$ 
Conclusions: As early as wk14, IV GLM demonstrated clinically meaningful improvements in skin $\mathrm{PsO}$ irrespective of MTX use and nail PsO. Improvement in DLQI was seen as early as wk8, w/continued improvement at wks 14 and 24.

Disclosure of Interest: P. Mease Grant/research support from: Janssen Research and Development, LLC, M. Husni Grant/research support from: Janssen Research and Development, LLC, S. Chakravarty Employee of: Janssen Scientific Affairs, LLC, S. Kafka Employee of: Janssen Scientific Affairs, LLC, D Harrison Employee of: Janssen Research and Development, LLC, D. Parenti Employee of: Janssen Scientific Affairs, LLC, L. Kim Employee of: Janssen Research and Development, LLC, K. Lo Employee of: Janssen Research and Development, LLC, E. Hsia Employee of: Janssen Research and Development, LLC, A. Kavanaugh Grant/research support from: Janssen Research and Development, LLC

DOI: 10.1136/annrheumdis-2018-eular.1766

\section{SAT0347 BASELINE CHARACTERISTICS OF PATIENTS WITH PSORIATIC ARTHRITIS INITIATED ON APREMILAST IN THE CORRONA PSORIATIC ARTHRITIS/ SPONDYLOARTHRITIS (PSA/SPA) REGISTRY}

P.J. Mease $^{1}$, E. Rosenstein ${ }^{2}$, H. Feng ${ }^{3}$, M. Liu ${ }^{3}$, B. Guerette ${ }^{4}$, L. Teng ${ }^{4}$, S. Rebello ${ }^{3}$, A.R. Ogdie-Beatty ${ }^{5} .{ }^{1}$ Swedish Medical Center and University of Washington School of Medicine, Seattle; ${ }^{2}$ Institute for Rheumatic and Autoimmune Diseases, Overlook Medical Center, Summit, ${ }^{3}$ Corrona, LLC, Southborough; ${ }^{4}$ Celgene Corporation, Summit; ${ }^{5}$ Department of Medicine, Division of Rheumatology, University of Pennsylvania, Philadelphia, USA

Background: Apremilast (APR) is an oral phosphodiesterase 4 inhibitor approved for the treatment of adult patients with active psoriatic arthritis (PsA) and psoriasis.

Objectives: To characterise demographics, disease activity and duration, concomitant therapy, quality of life, and prior comorbidities among patients with PsA who initiated APR in the Corrona Psoriatic Arthritis/Spondyloarthritis (PsA/SpA) registry, an independent, prospective, US observational cohort.

Methods: Adult patients $\geq 18$ years of age with PsA who were reported initiating APR in the Corrona PsA/SpA registry between May 2014 and September 2017 were included in the analysis. Descriptive statistics were calculated for patients' clinical characteristics and disease assessments at the index visit. The index visit was defined as the Corrona visit when APR initiation was reported. If the patient started a drug between 2 Corrona visits, the measures/outcomes from a prior visit were imputed to replace the missing values.

\begin{tabular}{|c|c|c|}
\hline \multicolumn{3}{|c|}{ Clinical Characteristics and Disease Assessments of PsA/SpA Patients at the Index Visit } \\
\hline Characteristic & $n^{*}$ & Mean (SD) \\
\hline Swollen joint count $(0-66)$ & 136 & $2.7(4.43)$ \\
\hline Tender joint count $(0-68)$ & 136 & $7.2(11.56)$ \\
\hline PhGA (VAS 0-100 mm) & 135 & $22.1(18.82)$ \\
\hline PtGA (VAS 0-100 mm) & 134 & $54.2(26.45)$ \\
\hline Dactylitis count (1-20) & $14 / 138$ & $2.6(2.21)^{5}$ \\
\hline SPARCC/Leeds Enthesitis Index (1-16) & $34 / 138$ & $4.2(3.05)^{5}$ \\
\hline DAS-28 (CRP) $(0-10)$ & 67 & $3.1(1.04)$ \\
\hline $\operatorname{CDAl}(0-76)$ & 128 & $13.9(9.57)$ \\
\hline CDAPSA (0-154) & 128 & $20.7(15.07)$ \\
\hline HAQ-S $(0-3)$ & 135 & $0.95(0.69)$ \\
\hline BASDAI (0-10) & 126 & $5.4(2.53)$ \\
\hline Morning stiffness (VAS 0-100 mm) & 134 & $54.4(28.26)$ \\
\hline \multicolumn{3}{|c|}{ 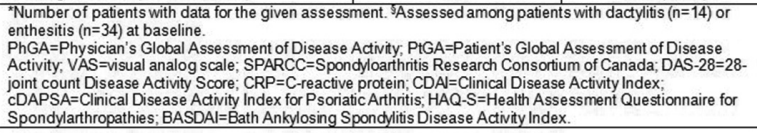 } \\
\hline
\end{tabular}

Results: Among 138 patients included in the analysis, mean (SD) age was $56^{12}$ years, mean (SD) BMI was $33,{ }^{7} 62 \%$ were female, $66 \%$ were previously on a nonbiologic DMARD (nbDMARD) and $79 \%$ had prior biologic use; $62 \%$ were on APR monotherapy. Of the APR initiators, the number of patients receiving concomitant methotrexate, nbDMARD, TNF inhibitor, and non-TNF inhibitor were 32 (23\%), 41 $(30 \%), 6(4 \%)$, and $4(3 \%)$, respectively. Pertinent comorbidities included diabetes mellitus $(22 \%)$, metabolic syndrome $(22 \%)$, cancer $(18 \%)$, cardiovascular disease $(17 \%)$, and congestive heart failure $(0.7 \%)$. Patients reported a mean (SD) of $13^{10}$ years for PsA symptoms and a mean (SD) of $10^{9}$ years since PsA diagnosis. Of the 94 patients with data available for evaluation, $14 \%$ met criteria for minimal disease activity while $1 \%$ met criteria for very low disease activity. Most patients had moderate or low levels of disease activity, respectively: CDAI (48\% and $35 \%)$, cDAPSA ( $47 \%$ and $34 \%$ ), and DAS-28 (CRP) (37\% and $21 \%$ ). Of note, $82 \%$ of patients had $<5$ swollen joints and $63 \%$ had $<5$ tender joints. Mean HAQ-S $(0-3)$ was 0.95 and BASDAI $(0-10)$ was 5.4 (Table). Patients demonstrated a substantial burden of disease with a mean fatigue score $(0-100)$ of 55 and mean overall pain score $(0-100)$ of 55 , and $81 \%$ reported stiffness lasting $>30$ min. Additionally, mean baseline work productivity and activity impairment (WPAI) subscale scores indicated limitations on absenteeism (8\%), presenteeism (25\%), work productivity loss (26\%), and activity impairment (40\%).

Conclusions: The population of patients with PsA treated with APR in the Corrona $\mathrm{PsA} / \mathrm{SpA}$ registry exhibited low to moderate disease activity and were substantially impacted, as evidenced by patient-reported outcomes (pain, fatigue, stiffness, and productivity). Future analyses on this cohort will provide more insight into patient characteristics and treatment patterns in this population, as well as long-term efficacy and safety information for PsA patients treated with APR.

Disclosure of Interest: P. Mease Grant/research support from: Abbott, Amgen, Biogen Idec, BMS, Celgene Corporation, Genentech, Janssen, Eli Lilly, Novartis, Pfizer, Roche, UCB, Consultant for: Abbott, Amgen, Biogen Idec, BMS, Celgene Corporation, Genentech, Janssen, Eli Lilly, Novartis, Pfizer, Roche, UCB, Speakers bureau: Abbott, Amgen, Biogen Idec, BMS, Genentech, Janssen, Eli Lilly, Pfizer, UCB, E. Rosenstein Grant/research support from: Biogen, Boehringer Ingelheim, Novartis, Consultant for: BMS, Boehringer Ingelheim, Speakers bureau: Amgen, BMS, H. Feng Employee of: Corrona, LLC, M. Liu Employee of: Corrona, LLC, B. Guerette Employee of: Celgene Corporation, L. Teng Employee of: Celgene Corporation, S. Rebello Employee of: Corrona, LLC, A. Ogdie-Beatty Grant/research support from: Pfizer, Novartis, Consultant for: Abbvie, BMS, Lilly, Pfizer, Novartis, Takeda

DOI: 10.1136/annrheumdis-2018-eular.3361

\section{SAT0348 SAFETY OF IXEKIZUMAB IN PATIENTS WITH PSORIATIC ARTHRITIS: RESULTS FROM A POOLED ANALYSIS OF THREE CLINICAL TRIALS}

P. Goupille ${ }^{1}$, E. Roussou ${ }^{2}$, G. Burmester ${ }^{3}$, P.J. Mease ${ }^{4}$, A.B. Gottlieb ${ }^{5}$, S. Garces ${ }^{6}$ O. Benichou', D. Adams ${ }^{6}$, W. Xu ${ }^{6}$, P. Nash ${ }^{8} .{ }^{1}$ University Hospital of Tours, Tours, France; ${ }^{2}$ King George Hospital, Essex, UK; ${ }^{3}$ Charité — University Medicine Berlin Free University and Humboldt University, Berlin, Germany; ${ }^{4}$ Swedish Medical Center, and University of Washington, Seattle; ${ }^{5}$ New York Medical College, New York; ${ }^{6}$ Eli Lilly and Company, Indianapolis, USA; ${ }^{7}$ Eli Lilly and Company, Paris, France; ${ }^{8}$ University of Queensland, Brisbane, Australia

Background: Ixekizumab (IXE), a high affinity monoclonal antibody that selectively targets interleukin-17A, has been shown to be superior to placebo (PBO) in improving signs and symptoms of psoriatic arthritis (PSA) in Phase 3 trials ${ }^{1,2}$.

Objectives: To assess the safety of IXE in patients with active PsA using data pooled from 3 (SPIRIT-P1, -P2, and -P3) Phase 3 trials.

Methods: SPIRIT-P $1^{1}$ and $-\mathrm{P} 2^{2}$ are double-blind trials; patients were randomised to $\mathrm{PBO}$, adalimumab (ADA; active reference arm; SPIRIT-P1 only), ${ }^{1}$ or $80 \mathrm{mg}$ IXE every $4(\mathrm{Q} 4 \mathrm{~W})$ or 2 (Q2W) weeks. PBO and ADA patients were re-randomised to either IXEQ4W or IXEQ2W for the open-label extension period (Weeks 24-156); patients who initially received IXE remained on their original dose. SPIRIT-P3 is an open-label (Week 36-64) trial where patients received IXEQ2W followed by a randomised withdrawal period. In all the 3 trials, patients received a $160 \mathrm{mg}$ loading dose of IXE. Safety data were integrated from all IXE-treated patients (defined as all patients receiving $\geq 1$ dose of IXE) included in SPIRIT-P1, -P2, and -P3. Exposure-adjusted incidence rates (IRs) per 100 patient-years (PY) were reported for adverse events (AEs)

Results: Overall, 1118 patients received IXE (total exposure $=1373.4$ PY). Four deaths (0.3/100PY) were reported (cerebrovascular accident, cardio-respiratory arrest, drowning, and pneumonia) (Table). The most common treatment-emergent AEs (TEAEs) were injection-site reaction (ISRs), upper respiratory tract infection, and nasopharyngitis; IRs for TEAEs, including ISRs, decreased overtime. There was no clinically meaningful increase in IRs of serious AEs, infections, serious infections, hypersensitivity, and major adverse cardiovascular events (MACE) with longer IXE exposure (Table). IR for serious infections was low (1.2/ 100PY). Serious infections included pneumonia (0.2/100PY), lower respiratory tract infection, and esophageal candidiasis (0.1/100PY each). No case of active tuberculosis (TB) was reported, but 1 case of latent TB was deemed as serious due to hospitalisation for testing to exclude active TB. Opportunistic infections were limited to oral and esophageal Candida and localised herpes zoster. There were no reports of deep organ or bloodstream Candida infections. No anaphylaxis was reported, but 1 patient $(0.1 / 100 \mathrm{PY})$ experienced angioedema. No patient had infections temporally associated with Grade $\geq 2$ neutropenia. Nine patients $(0.7 /$ $100 \mathrm{PY}$ ) had MACE. One case (0.1/100PY) each of Crohn's disease (with prior history of irritable bowel syndrome) and ulcerative colitis were reported. However, none of the 12 patients with pre-existing inflammatory bowel disease experienced an exacerbation with IXE. 